\title{
ESTRATEGIA GEOPOLITICA DEL AMAZONAS
}

\section{Por: Alfonso Gómez Orduz*}

\section{DINAMICA GEOPOLITICA DE COLOMBIA.}

Desde el punto de vista geopolítico, Colombia es un país con mentalidad mediterránea, es decir que la concepción espacial de los colombianos es terrestre. ${ }^{1}$ No tenemos una tradición marítima, que se refleje en una escasa proyección naval no sólo de las organizaciones de transporte sino de la infraestructura portuaria, la cual hoy en día no permite la construcción de naves de importancia marítima.' Se podría afimar sin pecar de exageración que el costeño se desarrolla de espaldas al mar y que su máxima aspiración es establecerse en el interior del país ${ }^{3}$.

La propaganda ambientalista en Colombia sostiene que el pueblo colombiano no tiene una cultura del agua ${ }^{4}$, entendida como uso racional de ésta para la conservación de los recurs os hídricos, pero el fondo es más profundo, el colombiano es un hombre con un atávico temor al río que lo obliga a alejarse, a darle la espalda, ahí que lo convierta en alcantarilla $a^{5}$ s ímplemente lo olvida. El que usa el río es el marginado, las comunidades ricas desarrollan comunicaciones ${ }^{6}$ terrestres y no fluviales, mucho menos maritimas; en definitiva somos hombres de tierra, seguimos las cuencas de los ríos para explotar sus tierras fértiles y no sus recurs os acuíferos.

El desarrollo histórico del poblamiento, condicionado por los factores morfológicos y climáticos ${ }^{7}$, generaron una dinámica de expansión prácticamente en el sentido de los meridianos y las cuencas de los dos ríos longitudinales colombianos encausaron una dinámica de crecimiento de nuestro Ecúmene ${ }^{8}$, en dirección Norte-sur, la cual nos permite en la actualidad trasladamos por tierra

\footnotetext{
* Profesor Universidad Pedagógica Nacional.

${ }^{1}$ El proceso de colonización en Colombia, por su origen histórico, se desarrolló de adentro hacia afuera, o sea de los centros urbanos hacia la periferia.

${ }^{2}$ El proceso de apertura ha demostrado daramente su ineficiencia, ha manifestado ser anticuado y no tiene la capacidad adecuada para los volúmenes de carga actuales.

${ }^{3}$ Lo prueban las grandes tasas de inmigrantes en las principales ciudades del país. En cambio las ciudades costeras se e stán "cachaquizando" por la al ta influencia de población proveniente del interior del país.

${ }^{4}$ Programa desarrollado básicamente por la Universidad de Antioquia. 1993.

${ }^{5}$ Carlos Agudelo. El Río Bogotá en el Muña es cadáver. (El Tiempo). Bogotá, 22 de mayo de 1994. p.IE.

${ }_{7}^{6}$ Ver Fals Borda. Río Magdalena.

7 Sorr Max. Fundamentos Biológicos de la Geografía Humana (Ensayo de una Ecología del Hombre). Editorial Juventud, Barcelona. 1955.

${ }^{8}$ El ejemplo dásico se da en la colonización antioqueña que se extiende por el valle del río Cauca, sobre el piso témico templado. Fundamentalmente Manizales, Armenia y Pereira.
} 
desde Rumichaca ${ }^{9}$ hasta Cartagena o Santa Marta en dos días a través de un adecuado sistema de troncales carreteables que se han desarrollado paralelas al sistema andino colombiano. Por el contrario es completamente imposible en el mismo tiempo desplazarnos por tierra de Bahía Solano a Puerto Carreño.

Indiscutiblemente lo que nos impide este desplazamiento son los tres sistemas cordilleranos de los Andes colombianos, que se constituyen hoy en dia en un obstáculo para nuestro sistema vial ${ }^{10}$.

El sistema vial de transversales es muy deficiente, lo cual impide la comunicación adecuada de las regiones orientales con el litoral Pacífico No existe prácticamente dinámica de crecimiento este-oeste; para el colombiano medio, prácticamente no existen la Amazonía, la Orinoquia ni mucho menos la franja costera pacífica. La visión oriental de la población corresponde al denominado piedem onte andino donde ha penetrado la espontánea colonización en los últimos cincuenta años. Desde el punto de vista geopolítico Colombia apenas está creciendo espacialmente en dirección sur-norte y norte-sur, a partir del triángulo de oro de nuestro país ${ }^{11}$, con un $65 \%$ de la superficie jurídica inexplorada, en espera de procesos de colonización y por consiguiente de asimilación real a nuestro Ecúmene; es to le permitiría la consolidación espacial del país y por consiguiente una verdadera soberanía nacional. Hace más de treinta años se iniciaron los procesos de expansión territorial en las tierras de Cesar, Magdalena Medio, el Sinú y la Sierra Nevada de Santa Marta, procesos que en la actualidad están en vía de consolidación; cuando esto se logre y los espacios baldíos territoriales desaparezcan, la dinámica de crecimiento del ecúmene colombiano cambiará su dirección en sentido de los Paralelos, debilitando su dinámica sur -norte, para enfrentarse decididamente a la conquista de la Amazonía y la Orinoquia proceso iniciado en la década del setenta ${ }^{12}$ y que podrá ser consolidado con pleno desarrollo después de cincuenta años, si no se presenta una conmoción mundial que lo estimule ${ }^{13}$.

Cuando Colombia logre asimilar a su economía la Orinoquia y fundamentalmente la Amazonía, se convertirá en un estado poderoso, estable y ampliamente desarrollado, inclusive con aspiraciones hegemónicas universales. Colombia es un Ecúmene con un potencial hegemónico; existen en nuestro país todas las condiciones geopolíticas para serlo, tan sólo falta «maduración espacial», adquisición y desarrollo de los espacios indispensables para lograrlo y consolidación del Heartland ${ }^{14}$. Esto se logrará a través de la colonización racional amazónica.

\footnotetext{
${ }^{9}$ Punta límite con el Ecuador.

${ }^{10}$ Para mayor comprensión ver Londoño L. Julio. Nueva Geopolítica de Colombia. Bogotá 1965.

${ }^{11}$ Bogotá, Cali, Medellín.

12 Motivados especialmente por la marihuana y la œoca en la actualidad.

${ }_{11}^{13}$ Algunas de origen dimático o por guerras.

${ }^{14}$ Ver Mackinder. Teoría de Dominación de la Tierra 


\section{DINAMICA GEOPOLITICA DE LOS PAISES AMAZONICOS.}

La Cuenca Amazónica presenta una superficie aproximada de tres y medio millones de kilómetros cuadrados, de los cuales 400.000 pertenecen a Colombia ${ }^{15}$, en donde se desarrolla la más extraordinaria selva ecuatorial del mundo; África no presenta una selva como ésta, no sólo por su superficie sino por su diversidad. Se dice que la Amazonía es la reserva de la humanidad, el pulmón del mundo, la región en donde se sostiene una mayor cantidad de especies de fitomasa y zoomasa por kilómetro cuadrado. Paralelamente, científicos muy prestigiosos sostienen que sus suelos son malos, muy ácidos, lixiviables, pobres en nutrientes, etc. Si la colonización penetra en la selva y la destruye generara un anal atentando contra la humanidad que perdería el $70 \%$ del oxígeno con la destrucción de la hilea amazónica. Todos los argumentos científicos ecologistas y conservacionistas son presentados hábilmente para sustentar las tes is anterioresson asimilados por los sectores académicos como dogmas incuestionables y se constituyen en inquisiciones modernas dispuestas a quemar en la hoguera al hombre que se atreva a cortar un árbol o ir en contra de sus teorías conservacionistas. Esta propaganda política se ha implementado sistemáticamente y con gran intensidad en los últimos 20 años en el mundo, con un énfasis muy especial en los países «dueños» de la cuenca amazónica, donde se financia ${ }^{16}$ generosamente la ecología y el conservacionismo tendientes a generar una cultura ambiental, que le permita mantener una reserva territorial en la Amazonía. Con lo anterior se condenan o impiden los intentos de los países amazónicos de consolidarse territorial-mente en el área. El panorama que se observa es el siguiente:

2.1 En Colombia los diferentes órganos de planeación desde hace mucho tiempo han entendido que el desarrollo del país está en las regiones orientales, han diseñado planes viales de colonización que van de simples vías a complejos planes de desarrollo económico, los cuales se han quedado en el papel y cuya implementación se ha retardado tanto que se ha constituido en obstáculo para el desarrollo regional ${ }^{17}$.

Nunca han planteado objetivos a largo plazo, proyectables en el tiempo; todo proyecto viable ha sido sus tituido o modificado por otro, anarquizando en tal forma la inversión que ha retardado el progreso vial económico y social causando una profunda insatisfacción social, utilizada políticamente por la subversión y constituyendo el mayor obstáculo para el desarrollo actual de la región amazónica.

Así, muchas de las temáticas ambientalistas del actual Congreso entran en profunda contradicción con la realidad geográfica de las ricas tierras del Caquetá,

\footnotetext{
15 Otros autores so stienen bajo otros criterios su perficies diferentes como es el caso de Domínguez Camilo. Amazonía Colombiana. Banco Popular. 1985

${ }_{17}^{16}$ Como es el caso holandés para Colombia.

${ }^{17}$ Como es el caso de Operación Colombia.1952-53. La Marginal de la Selva.
} 
cuya fertilidad y productividad saltan a la vista; la selva se tumbó y no se produjo

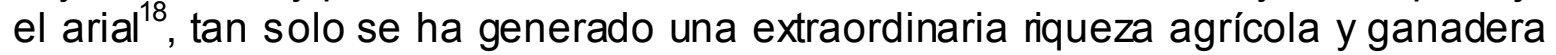
que lucha contra el embotellamiento vial y la carencia de definidos planes de desarrollo por parte del es tado.

2.2 En el Brasil, en contraposición a Colombia se presentan planes definidos de consolidación y expansión territorial ${ }^{19}$ diseñados des de antes de su independencia por el Barón de RIOBRANCO, quien fija los objetivos a largo plazo, los cuales no han sido modificados y se han constituido en la meta máxima del Imperio Brasilero. $^{20}$

Este país ha logrado desarrollar una dinámica de expansión del ecúmene a través de la creación de polos artificiales de atracción, como fue el caso de Manaos en el siglo pasado y el de Brasilia en la actualidad, ambos implementados con gigantescos sistemas de comunicación vial ${ }^{21}$ a través de los cuales se ha estimulado una sistemática colonización que ha generado una dinámica territorial hacia el occidente, creando así una "cultura del agua», fundamentalmente amazónica. La colonización ha sido consolidada allí no sólo a través de la agricultura y la ganadería, sino con la minería y la industria, sectores que se constituyen en la actualidad en el factor migratorio de mayor envergadura y por medio del cual se ven afectados territorios de Colombia y Venezuela. El Brasil configura sus espacios amazónicos con una gran claridad geopolítica. Desama las tesis ecologistas que lo condenaban como destructor del patrimonio de la humanidad en el encuentro de Río de Janeiro. Es el único estado que presenta claras aspiraciones territoriales en la cuenca amazónica, es el único que entiende que su grandeza depende de la conquista y desarrollo del Amazonas ${ }^{22}$.

2.3 En el imperio inca, durante su etapa de mayor expansión, no se han extendido sus dominios en la cuenca amazónica; podría afimarse que su territorio ha sido limitado por la humedad. La dinámica del ecúmene peruano es costera, limitada por los Andes y la cultura quechua. Los territorios amazónicos son el resultado de una ambición hegemónica no secundada por la expansión territorial, los cholos no han emprendido la colonización ${ }^{23}$ presionados se han desplazado hacia el oriente. La his toria negra de las casas caucheras con todo su desarrollo territorial no ha logrado el establecimiento del indígena serrano en la hilea amazónica. Los fracasos de la colonización peruana obligaron ${ }^{24}$ a los gobernantes peruanos a permitir el establecimiento reciente de una gran colonización japonesa, además

\footnotetext{
${ }^{18}$ Ver Manrique Sabogal. Caminos del Desierto Verde. El Tiempo. Mayo de 1994.

${ }^{19}$ Ver Do Couto Silva, Golbery. Geopolítica del Brasil.

${ }^{20}$ Schilling Paulo. El Expansionismo Brasilero. Cid Editores, Argentina. 1978.

${ }^{21}$ Ver cuadro anexo No. 1

${ }^{22}$ Travassos Marco. Proyección Continental del Brasil. Editorial Cid, Argentina. 1978.

${ }^{23}$ Fawcett PH. Las Expediciones del Coronel Fawcett. Editorial Argos, Barcelona.

${ }^{24}$ Ver Plan Inca desarrollado porla Junta Militar Peruana. 1970. 
del establecimiento de factorías gubernamentales extractoras de madera en los puntos estratégicos fronterizos, apoyados por bases militares ${ }^{25}$.

La revolución inca desarrollada por las fuerzas militares peruanas está dando sus frutos, con el fin de unificar en un solo ecúmene el territorio nacional y destruir la dicotomía blanco-cholo; cuando esto se logre totalmente, su dinámica de crecimiento se desviará hacia la Amazonía, y surgirán nuevamente las viejas aspiraciones cimentadas por la casa Arana sobre Leguízamo, la Pedrera y toda la margen derecha del río Caquetá desde su nacimiento hasta las bocas de Apaponis.

2.4 En el Ecuador se explica que es y será un país amazónico; es la frase inculcada por el sector educativo a los ecuatorianos ${ }^{26}$. Sin embargo las determinantes morfológicas afirman lo contrario $y$, en la actualidad, la dinámica de crecimiento ecuatoriana se dirige hacia el occidente, hacia el pacífico; sus riquezas atraen a los habitantes, dándoles con esto la espalda a la Amazonía, a pesar de que sus intereses estratégicos los han obligado a enfrentarse militarmente al Penú para tratar de recuperar los territorios arrebatados por este país. La presencia militar ecuatoriana es muy fuerte y dispuesta a enfrentar las guarniciones fronterizas peruanas ${ }^{27}$. Ante su imposibilidad amazónica el Ecuador ha desarrollado fuertes vínculos económicos, políticos y sociales con Brasil a través del pacto Amazónico, la Trans-oceánica y el tratado de puertos libres.

2.5 En Bolivia se dice que las altas montañas andinas constituyen su territorio; Santa Cruz es Brasil. ${ }^{28}$ Expresión que indica una dinámica geopolítica clara. La gran aspiración boliviana es la recuperación de la costa pacifica, su salida al mar; la dinámica amazónica la desarrolla Santa $\mathrm{Cruz}^{29}$ como una unidad «diferente» que vive del petróleo y la economía brasileña. Podría afimarse que Bolivia no tiene una expresión amazónica.

\section{DETERMINANTES GEOPOLITICAS DE LA CUENCA AMAZONICA.}

La cuenca del Amazonas es una unidad creada para unir la cuenca del Plata y la del Orinoco y en cuyos extremos se desarrollan los plegamientos andinos y las formas antiguas de los macizos guayanés y brasilero. Es una unidad centro a través de la cual fluirán las otras unidades geopolíticas de América del Sur. Es el receptáculo natural del crecimiento de los países anteriomente citados, además

\footnotetext{
${ }^{25}$ Como es el caso del Alamo en el Rio Yaguez uno de los puntos estratégicos del trapecio amazónico colombiano. Recordemos que el Alamo es el fuerte dave en la pérdida mexicana del Estado de Texas.

${ }^{26}$ Ver Franklin Albert. Ecuador. Retrato de un Pueblo. Ed. Claridad, Buenos Aires 1945.

${ }^{27}$ Briceño, Justo. Geopolítica y Geoestrategia Americana. Pleamar 1966.

${ }^{28}$ Schilling, Paulo. Ver ExpansionismO Brasilero. Ed. Cid, 1978.

${ }^{29}$ Boscovich, Nicolás. Geoestrategia de la Cuenca del Plata. 1979. Buenos Aires.
} 
de haberse constituido en el único gran espacio, relativamente vacío, que permite la consolidación acelerada de un nuevo ecúmene desarrollado natural o artificialmente a través de masivas migraciones $y$, que junto con la tecnología adecuada, podrá en muy corto plazo explotar sus inmensos recursos edáficos, fitológicos, zoológicos y del subsuelo con el fin de sostener y desarrollar una población de más de cien millones de habitantes sin ningún tipo de dependencia externa. Esta fue la motivación de los alemanes con su invasión al Brasil en 1942, yen la actualidad motiva a las grandes potencias del mundo.

De otra forma no se entiende cómo las grandes potencias mundiales invierten inmensas cantidades de dinero en estudios sobre la cuenca amazónica que van desde prospección geofísica a comportamiento de los primates, pasando por los estudios antropológicos, sociológicos, de flora y fauna, etc., desarrollados por japoneses, holandeses, alemanes, rusos, norteamericanos, suizos, chinos, ingleses, etc. Es impresionante el gran número de estudios de prospección remota sobre la Amazonia ${ }^{30}$ en especial de origen francés. Y entonces surgen preguntas como: ¿A qué obedece tanta inversión y preocupación científica? ¿Por qué la Unión Soviética y los Estados Unidos desde el principio de la Guerra Fría firmaron el Tratado de No Proliferación de Armas Atómicas en América del Sur? ¿Por qué se conocen escasamente los estudios de seguridad atómica? ¿Por qué no se informa al mundo sobre cuáles son los santuarios de seguridad en caso de una posible guerra atómica?

Si se diera respuesta a las anteriores preguntas encontraríamos que la cuenca amazónica es prácticamente el único refugio en caso de una guerra termo-nuclear y que por lo menos 500.000 kilómetros cuadrados de superficie amazónica no serían afectados por la radiactividad que si contaminaría el resto del mundo a través de los vientos y las corrientes marinas. El sistema de flujos atmosféricos normales sería modificado por las descargas nucleares explotadas en el hemisferio norte, entre tres mil y cuatro mil ojibas nucleares estallarían en Norte América, Europa Occidental, Rusia y China generando baj ísimas presiones atmosféricas que desviarían los vientos hacia ellas, fortaleciendo la zona de calmas ecuatoriales amazónica a la cual difícilmente afectaría la radiación atómica.

Esta es la verdadera razón por la cual la Amazonía debe pemanecer baldía; no debe ser poblada ni mucho menos desarrollada por los países amazónicos. No debe destruirse el pulmón del mundo. Esa es su gran importancia geopolítica; cuando la guerra temine, los desechos humanos de las grandes potencias involucradas saldrán de sus refugios atómicos y se trasladarán a la Amazonía que se convertirá en la tierra prometida de la nueva era post-atómica.

\footnotetext{
${ }^{30}$ En el VI Simposio Latinoamericano de Percepción Remota. Cartagena 3-8 octubre de 1993. Se presentaron 21 ponencias de Percpción remota sobre la Amazonia.
} 